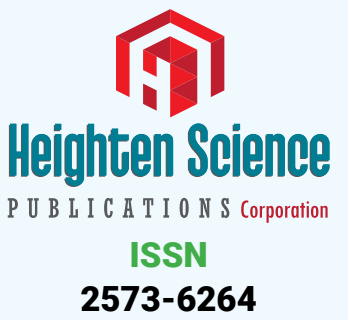

2573-6264

\title{
TRIA-MF protocol as an innovative tool in the comprehensive treatment and outcome evaluation of lower limb amputees before and after
} prosthesis use

\author{
Maurizio Falso', Silvia Zani ${ }^{1}$, Eleonora Cattaneo ${ }^{2}$, Marco \\ Zucchini $^{3}$ and Franco Zucchini ${ }^{3}$ \\ 'Middle Cares Rehabilitation Unit, Fondazione Madonna del Corlo, Lonato (Bs), Italy \\ ${ }^{2}$ Section of Neurological Rehabilitation, Clinical Institute Città di Brescia, Brescia, Italy \\ ${ }^{3}$ Poliortopedia, Brescia, Italy
}

\begin{abstract}
*Address for Correspondence: Maurizio Falso, MD Physical Medicine and Rehabilitation, Middle Cares Rehabilitation Unit, Fondazione Madonna del Corlo, Corso Garibaldi 3, 25017, Lonato (Bs), Italy, Tel: 349.4971729; Email: falsomaurizio@libero.it

Submitted: 31 December 2018

Approved: 17 January 2019

Published: 18 January 2019

Copyright: (c) 2019 Falso M, et al. This is an open access article distributed under the Creative Commons Attribution License, which permits unrestricted use, distribution, and reproduction in any medium, provided the original work is properly cited
\end{abstract}

Abbreviations: TRIA-MF: Amputees Integrated Rehabilitative Treatment- Maurizio Falso; POP Post-Operation; TF: Trans-Femoral; TT: TransTibial; K-level: Kode-level; A: Amputation; TP: Temporary Prosthesis; DP: Definitive Prosthesis: FKT: Physiokynesis therapy; PCC: Pearson Correlation Coefficient

Check for updates

\section{Abstract}

Background: A structured multidisciplinary team is very important during every phase of the amputation process and a good communicative team guarantees a greater tranquility for the patient, thanks to more homogenous information, that is already discussed between the clinicians.

Aim: The aim of this study was to define the efficacy and outcome value of an innovative procedure tool (TRIA-MF protocol) in the treatment of lower limb amputees before and after prosthesis use with the purpose to quantify the quality of the procedure and its economic impact on the clinical patients' recovery.

Setting: A rehabilitation institute for the treatment of neurological and orthopaedic gait disorders.

Methods: 12 patients (4 women and 8 males) subjected to lower limb amputation and admitted according to the principles of inclusion criteria of the TRIA-MF protocol at the Rehabilitation Department of the Clinical Institute Città di Brescia were recruited in this study. All patients were included in an integrated and task-specific management protocol of the amputee, which allowed to follow the rehabilitation process from amputation to the final restoration, for a period of 6 months for each patient. Patients were evaluated 5 times during the study, collecting their degree of pain (VAS), their independence profile (Barthel Index) and the cirtometry of their amputation stump. Data on the duration of their admission to the rehabilitation unit, the inter-time between the amputation and acquisition of the temporary prosthesis, and between temporary prosthesis acquisition and the final prosthesis acquisition were also reported.

Results: Patients of our sample, at the end of their hospitalization, highlight a significant modification of the temporal data at 1 month and 6 months from their hospital discharge. A statistical significant increase of the Barthel Index value was observed in all patients recruited in this study proceeding from time TO to time T4; in the same way, a statistical significant decrease of the VAS scale was observed in all patients recruited proceeding from time T0 to time T4; the cirtometry of the amputation stump (expressed in $\mathrm{cm}$ ) showed a statistical significant decrease in all patients recruited proceeding from time T0 to time T4. We haven't observed a statistical significant correlation between the duration of the rehabilitative hospitalization and our clinical data; no statistical significant correlation was observed between the amputation stump cirtometry time-related modification and our intertime data.

Conclusion: The protocol was found to be a clear and relevant tool with the definition of the operational profile for each single professional figure involved; it could also be considered as an optimal tool for coding the management and evaluation of the effectiveness of amputee treatment, with a related high reproducibility, sensitivity and specificity profile. In line with the literature, the TRIA-MF protocol has allowed us not to exceed a period of hospitalization in rehabilitation units of more than 23 days, thus showing that it is an excellent tool for optimizing the management costs of the amputee over time. 


\section{Introduction}

Amputation is a surgical technique, which has always been used in history. The word "amputation" is used for the first time by Seneca in the $1^{\text {st }}$ century A.D. This word refers to an agricultural kind of terminology; infact it means "cut off all around", from the Greek form "amphi" (around/on both sides) and from the Latin form "putare" (cut off/trim) [1]. A person needs an amputation for different causes, but in the occidental countries we can recognize six main causes: a. systemic diseases like peripheral obliterative arteriopathy (3-5\% in people between 50/60 years of age, and $20 \%$ in people over-75) and diabetic vasculopathy; b. infections; c. traumas; d. tuberculosis; e. malign tumors; f. lower limb gangrenes [2]. In the last 18 years, in Italy there were 4877 arteriopathic patients who needed a lower limb amputation, as a consequence of their illness. $66 \%$ of them were major amputations, of which $73 \%$ trans-femoral amputees while only $34 \%$ were partial foot or toe amputations. During the same year in Italy there were a total number of 13.181 amputations both lower and upper limb, and a total of 5.359 elderly people amputations. Male elderly people have a prevalence of $93.5 \%$ every 100.000 inhabitants, almost twice as much as female population, with a prevalence of $55.9 \%$ every 100.000 inhabitants. The main period of italian hospitalization for any lower limb amputation is about 20 days, and 23 days for major amputations [3]. In Europe diabetic management costs are various: from $1.305 € /$ year in Spain, to $3.576 € /$ year in Germany. In Italy the main cost is about $2.990 € /$ year, for a national expenditure of 5 billion euros every year [4-6]. $60 \%$ of this expenditure is caused by in-hospital care, other for ambulatorial cares and drugs. In 2009, 105.000 recovery for diabetes were needed, for an in-hospital period of 9 days. Amputation is a major surgical intervention, that has an enormous, both physical and psychological, impact on the patient's life. Amputation can generate different emotions. Some of them can be useful and constructive, like relief, hope or euphoria. Other are very negative, such as rage, sadness, rejection, anxiety distress, uncertain, vulnerability and feeling of mutilation. All these feelings are very common for every disabling illness, but they are stronger for amputees. Amputation determinates an enormous alteration between body image and the true body, an unbearable loss. Even if a little percentage of all amputees become chronically depressed, it is very important to early treat any psychological difficulties, because they can negatively affect the rehabilitation process [7-10]. The main goals during the immediate postoperative phase relate to wound healing, pain control, forming of the amputation stump and early mobilization. A correct stump management starts after the operation and it's the main goal during the first two weeks before the provisory prosthesis use. Stump management concerns wound healing, edema reduction and contracture prevention. These early interventions are essential for a correct and functional prosthesis use. In this process it is necessary to correctly educate the patient to a correct stump care. After the amputation the stump presents an edema. This is caused by a vascular and lymphatic alteration, due to the surgical operation. In trans-tibial amputations, edema can negatively affect wound healing, because of an increased pressure in the stump that can increase tension on the suture, with rare skin necrosis [7,11-13]. When the drainage is removed, it's important to start the process of edema reduction. More recent soft silicon liner are used for postoperative edema reduction. These liners produce a uniform compression that shapes the stump, avoiding pear-shaping or not coniform or cylindrical shapes. A structured multidisciplinary team is very important during every phase of the amputation process. The guidelines suggest that this team should be composed by the surgeon, the rehabilitation physician, the anesthesiologist, the nurses, the physiotherapist and, if possible, the orthotic technician or the prosthetist. Depending to the circumstances the occupational therapist, the healthcare psychologist, the activity coordinator, the social worker, the dietician, the pastoral cares can be involved too. A good communicative team guarantees a greater tranquility for the patient, thanks to more homogenous information, that is already discussed between the clinicians. Every change in the treatment must be explained and discussed with the patient, in order to reach the objectives better suiting the patient's future needs [14-17]. 
The aim of this study was to define the efficacy and outcome value of an innovative procedure tool (TRIA-MF protocol) in the treatment of lower limb amputees before and after prosthesis use with the purpose to quantify the quality of the procedure and its economic impact on the clinical patients' recovery.

\section{Methods}

\section{Subjects}

The study was conducted on a selected sample of 12 patients ( 4 women and 8 males) subjected to lower limb amputation and admitted according to the principles of inclusion criteria of the TRIA-MF protocol at the Rehabilitation Department of the Clinical Institute Città di Brescia. The mean age of patients in our study sample was 73.5 years (+/- 8.2). Patients were recruited according to the transferability (or inclusion) criteria of the patient amputated from the acute rehabilitation surgical department. Table 1 summarizes analytically the profile of our study sample, recruited from January 2017 to January 2018, with acquisition of age, sex, level of amputation, shape of the stump, presence or absence of sensation of phantom limb and phantom pain, used analgesic drugs, POP liner used, presence of edema of the stump and K-level performing. In order to make the study sample as homogeneous as possible in its recruitment characteristics in the INDOOR phase we have adopted the criteria of transferability (or inclusion) of the patient amputated from the acute rehabilitation surgical department, foreseen in the outdoor phase of the protocol. In accordance with our inclusion criteria (• post-surgical drainage removed; • stump-free skin due to damage or continuity solutions implying a drastic slow-down or obstacle to the preparation path of the stump to the post-surgical modeling and preparation of the prosthesis; - the patient has already been reported to the orthopedic technician responsible for packaging the prosthesis, so that after an accurate observation of the amputation and detection of its cirtometry, he/she immediately provides the silicone cap preparation and reduction of post-surgical stump edema; • reporting to the doctor responsible for the rehabilitative path of the patient's obvious clinical stability with an individual level and degree of co-morbidity that does not hamper the process of functional recovery before and after prosthetics; - signaling to the Department nurse chief the necessities and needs of nursing management of the patient and of the relative needs of post-institutionalization social-assistance) we recruited 7 trans-femoral amputees ( 3 on the right lower limb and 4 on the left side), 4 trans-tibial amputees ( 1 on the right lower limb and 3 on the left side) and 1 bilateral trans-tibial amputee.

\section{TRIA-MF protocol}

- The TRIA-MF protocol is a clinical protocol for the amputee integrated management. This protocol integrates all the guidelines procedure and the more innovative procedure, to create the best care and rehabilitative treatment. The main aims of the TRIA-MF protocol are long-lasting patient's mobilization, assistance costs reduction, optimal stump modelling by the silicon liner use which prepares the stump for a successive prosthesis, team work by creating an integrated management protocol. This protocol includes three phases, according to guidelines rehabilitative treatments:Outdoor phase: this treatment phase is so called because patients are not treated in the rehabilitation unit, but in the surgical unit; during this phase the aim of the treatment is to avoid secondary damages, start the in-bed rehabilitation program and the occupational therapy for self-care management;

- In-between phase: this phase starts during the outdoor phase and finishes during the indoor one; during this phase the aim of the treatment is to manage the stump edema correctly, creating a correct stump shape;

- Indoor phase: this phase starts when the patient is transferred to the 
rehabilitation unit; this phase can be described as the real rehabilitative phase of our protocol. In this phase we described two rehabilitative underphases: pre-prosthesis phase (the patient's trained for a future prosthesis use; during this phase some of the aims are the same of the in-between phase, because of their overlap; post-prosthesis phase (this underphase starts when the patien is supplied by his preliminary prosthesis; during this phase patient must be trained to a good prosthesis use and device care).

The protocol structure and main passages of the TRIA-MF protocol are described in figure 1.

\section{Outdoor phase}

This first phase starts when the patient arrives to the hospital for the amputation surgery. The time course of this phase is between 6 to 9 days. The patient is hospitalized in an operative unit of vascular or orthotic surgery. This phase ends when the patient is stable enough to be transferred on an in-hospital rehabilitation unit or to start a rehabilitative service. This phase can be separated in two complementary and sometimes overlap phases:

Pre-surgical and preliminary post-surgical phases: during this period the patient isn't included in the study yet. The patient starts a standard rehabilitative program in order to prepare him to the amputation process and to start the first post-surgical interventions that are common for every patient. In these phases a prosthesis evaluation isn't possible yet.

Immediate post-surgical phase or preliminary outdoor phase: this can be described like the real first phase of our protocol. During this phase the patient starts a rehabilitation program in prevision to a rehabilitation unit transfer for the prosthesis prescription.

\section{Pre-surgical and preliminary post-surgical phase (Table 1)}

This preliminary phase is needed to prepare the patient for the surgical operation and the successive rehabilitation. In fact, it's important to remember that better

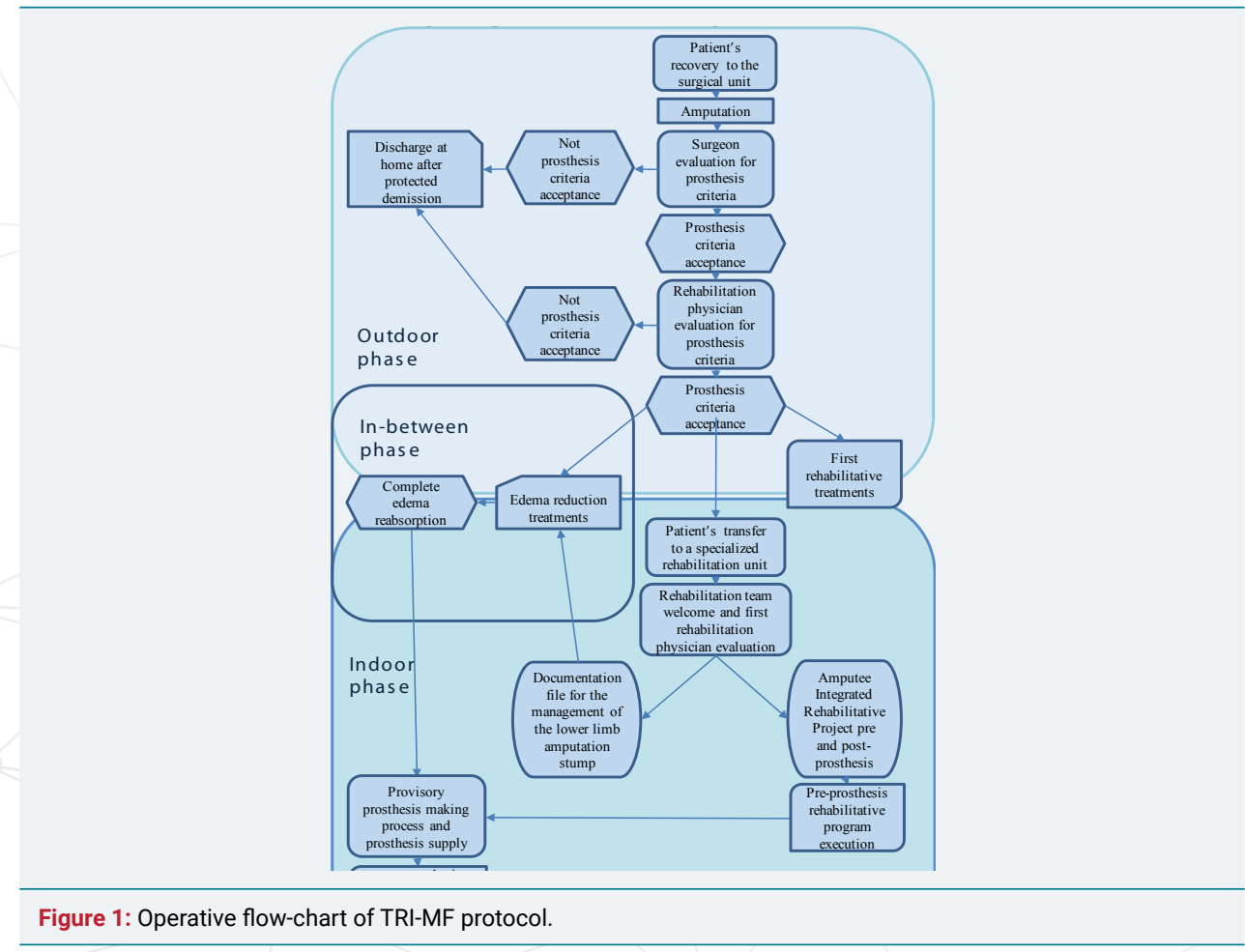




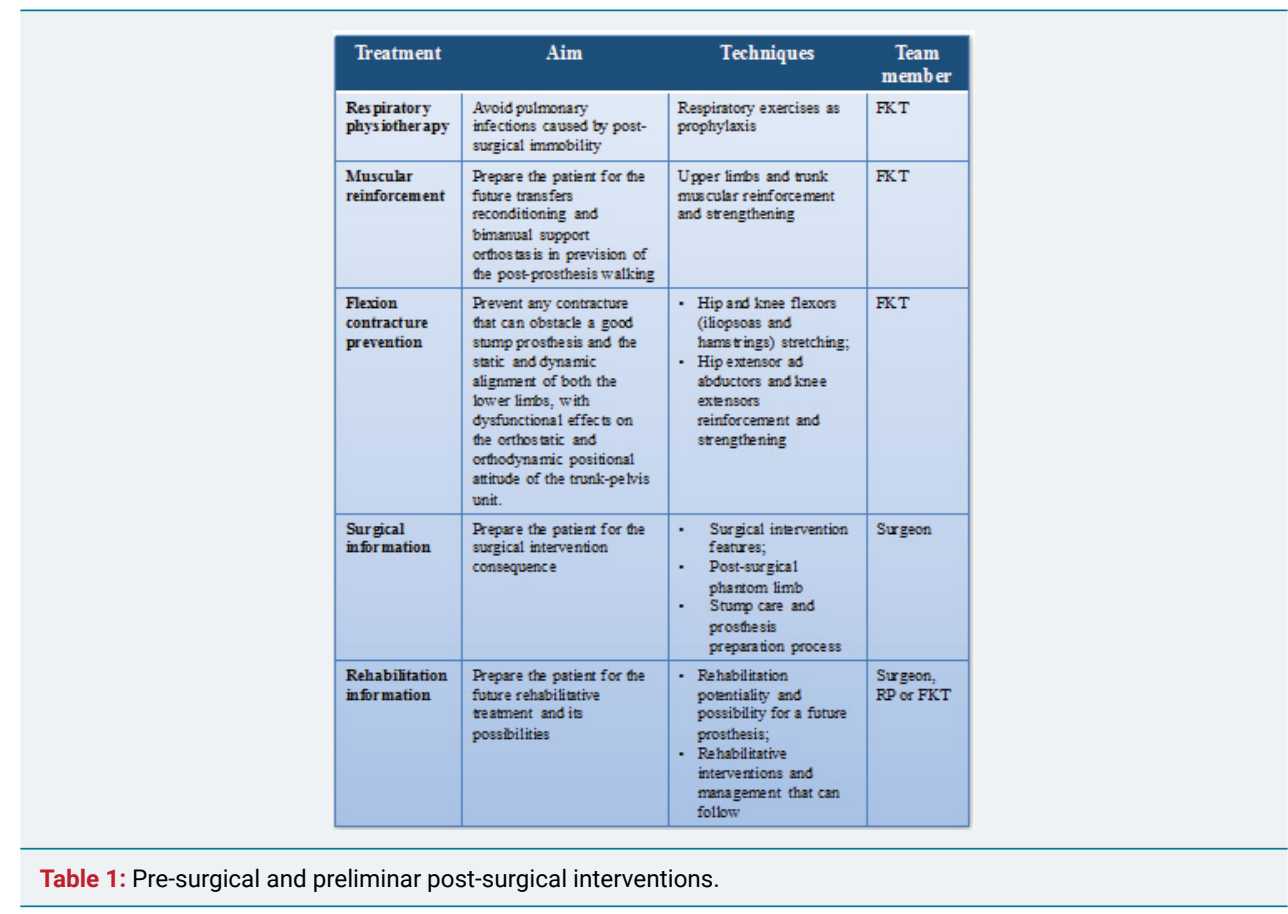

pre-surgical conditions correspond to better post-surgical conditions and a better rehabilitation. During this phase it's also important the patient's information about the intervention consequences and possibilities.

Rehabilitative project and program. During this phase the main interventions are:

1. Respiratory physiotherapy;

2. Muscular reinforcement;

3. Flexion contracture prevention;

4. Surgical information;

5. Rehabilitation information.

\section{Immediate post-surgical phase or preliminary outdoor phase}

This phase is possible only if the surgery unit presents a rehabilitative unit or a rehabilitative service. During this phase, the patient mustn't move, remaining in a forced immobility state. Because of this the team work became very important: physiotherapists and ward nurses must cooperate. Right after the operation, the patient's care and treatment consists of in-bed and just around mobility, with ward team supervision. During all this period, the patient stays in the surgery unit, starting from the day after the operation until the discharge.

Advantages of the TRIA-MF protocol: The TRIA-MF protocol expected an early patient treatment, to improve the amputee rehabilitation. An early treatment, especially if associate to a pre-operation treatment, is very important for the patient's future outcome. The rehabilitation program in this phase has the aim to prevent secondary damages caused by the surgical operation and his constriction in bed. Our protocol expected an early psychological treatment, to help the patient to overcome this traumatic phase, such as described by the literature.

Rehabilitative project and program: During this phase we used 9 different treatment approaches, according to patient's conditions (Tables 2.1, 2.2 and 2.3):

1. Respiratory physiotherapy; 


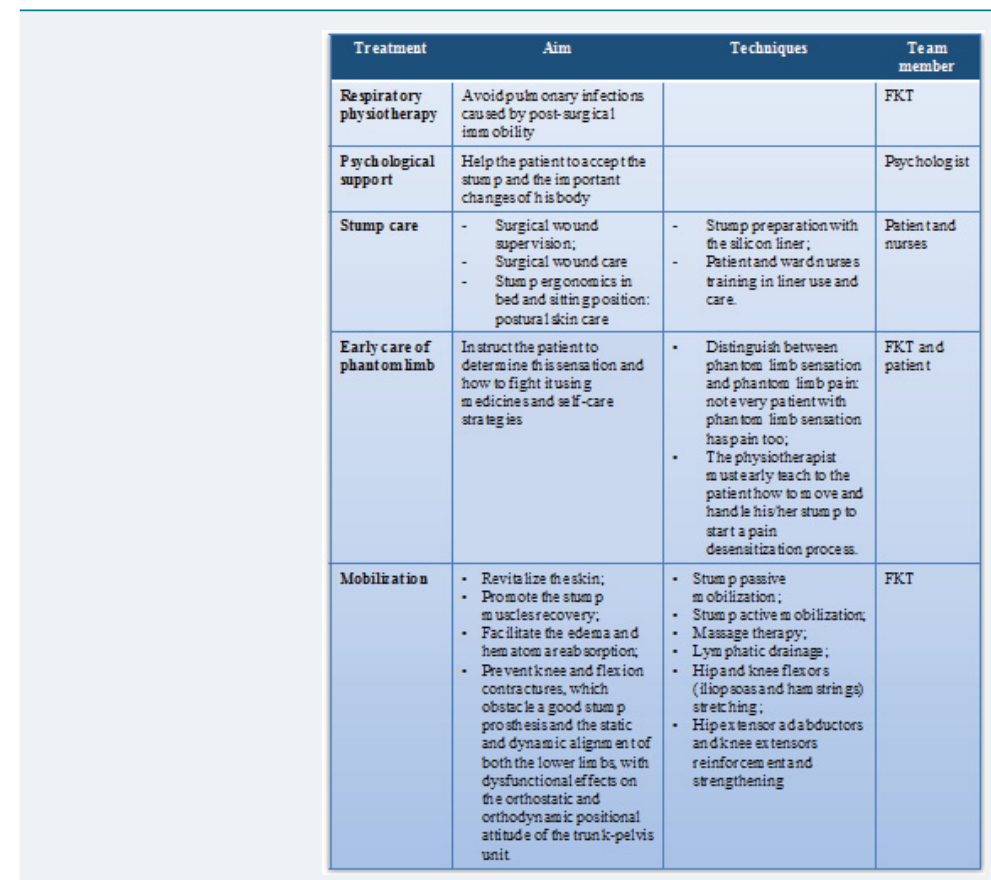

Table 2.1: Immediate post-surgical phase or preliminary outdoor phase.

\begin{tabular}{|c|c|c|c|}
\hline Treatment & Aim & Techniques & $\begin{array}{c}\text { Team } \\
\text { member }\end{array}$ \\
\hline $\begin{array}{l}\text { P'revention of } \\
\text { stump } \\
\text { myoarticulalar } \\
\text { damages }\end{array}$ & 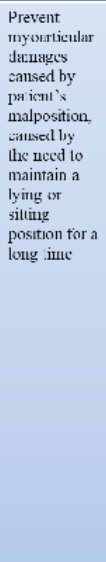 & 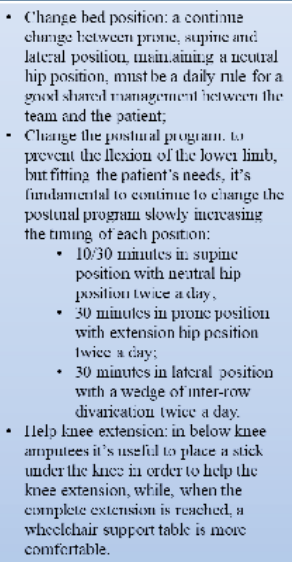 & $\begin{array}{l}\text { l:KI: murses } \\
\text { and pulticut }\end{array}$ \\
\hline
\end{tabular}

Table 2.2: Immediate post-surgical phase or preliminary outdoor phase.

\begin{tabular}{|c|c|c|c|}
\hline Treatment & Aim & Techniques & $\begin{array}{c}\text { Team } \\
\text { member }\end{array}$ \\
\hline $\begin{array}{l}\text { Cleaning } \\
\text { training }\end{array}$ & & $\begin{array}{l}\text { - Right after the operation the patient is } \\
\text { w ashed by ynurses in bed } \\
\text { When he reaches a minimal and } \\
\text { progressive auto-management and sitting } \\
\text { stance he can start to recover self-care and } \\
\text { personal hygiene skills in the battroom } \\
\text { with help }\end{array}$ & $\begin{array}{l}\text { Ward } \\
\text { nurses or } \\
\text { care-giver }\end{array}$ \\
\hline $\begin{array}{l}\text { Dressing } \\
\text { train ing }\end{array}$ & & $\begin{array}{l}\text { - Lower dothes: } \\
\text { Unilateral amputee: he she can dress up } \\
\text { 1aying on his her side and arching to } \\
\text { pull the dothes up his her legs. } \\
\text { - Bilater al amputee: he she can easily } \\
\text { dress up rolling from a side to the other. } \\
\text { - Upper cothes: to wear these cothes a } \\
\text { good sitting balance is necessary, so itis } \\
\text { easier when he she is sitting on the bed, }\end{array}$ & FKT \\
\hline $\begin{array}{l}\text { Autonomous } \\
\text { movements }\end{array}$ & & $\begin{array}{l}\text { - To do this it's necessary for the amputee to } \\
\text { have a good compliance in the early post- } \\
\text { surgical phase. The physiotherapist can } \\
\text { teach to the patient how to move from the } \\
\text { bed to the wheelchair and vice versa in } \\
\text { three efifferent ways: } \\
\text { : Pivotal movement, } \\
\text { - Back and forth movement, } \\
\text { Sliding on a table. }\end{array}$ & FKT \\
\hline
\end{tabular}

Table 2.3: Immediate post-surgical phase or preliminary outdoor phase. 
2. Psychological support;

3. Stump care;

4. Early care of phantom limb;

5. Mobilization;

6. Prevention of stump myoarticular damages;

7. Cleaning training;

8. Dressing training;

9. Autonomous movements.

\section{Professional figures interventions}

During this phase different team figures cooperate for the best patient's treatment, as described in the table 3 .

\section{In-between phase}

This phase is superimposed on the indoor and the outdoor phases. It can start when the patient's conditions allow the silicon liner to be use, in order to start a stump remodeling process. Because of the personal variabilities it can indifferently start when the patient is recovered in the surgical or in the rehabilitative unit. This phase finishes when the stump cytometry becomes stable, and the silicon liner use can be stopped. It's important to remember that the stump management is included in the pre-prosthesis preparation. The time-course of this phases must stay between a minimum of $3 / 5$ days to a maximum of $12 / 15$ days. This is important because after the parameter's stabilization, it is possible to apply a temporary prosthesis, which will be designed and made by the orthotic technician.

\section{Advantages of the TRIA-MF edema management (Table 4)}

The aim of this phase is to manage the post-surgical edema that occurs as a consequence of the surgical operation. In the TRIA-MF protocol we emphasize the early edema treatment and a stump gradual modelling, so we decided to use the silicon liners TTm/TFm pop, also called liner, which guarantees a uniform and constant segmental compression. There are two liner types, which can be used for the daily compressive therapy: a. TTpop liner (silicon liner for trans-tibial prosthesis); b. TFpop

\begin{tabular}{|l|l|l|}
\hline \begin{tabular}{|l|l|} 
Professional \\
figure
\end{tabular} & \multicolumn{1}{|c|}{ Task-specific intervention } & \multicolumn{1}{|c|}{ Timing } \\
\hline $\begin{array}{l}\text { Referring } \\
\text { surgeon }\end{array}$ & $\begin{array}{l}\text { - Post-surgical patients evaluation; } \\
\text { - Definition of the patients' prosthesis use } \\
\text { suitability; } \\
\text { Rehabilitation physician's call for every patient } \\
\text { who agree with suitability criteria; } \\
\text { - Outdoor rehabilitative project actuation after } \\
\text { the rehabilitative physician accordance. }\end{array}$ & $\begin{array}{l}\text { The operation day } \\
\text { or the day after }\end{array}$ \\
\hline Ward nurses & $\begin{array}{l}\text { - Stump care: skin care and surgical wound } \\
\text { medication; } \\
\text { - Prevention of stump myoarticular damages; } \\
\text { - Cleaning training; } \\
\text { - Patient's supervision. }\end{array}$ & Every two days; \\
\hline Physiotherapist & $\begin{array}{l}\text { - Respiratory physiotherapy; } \\
\text { - Early care of phantom limb; } \\
\text { - Mobilization; } \\
\text { - Prevention of stump myoarticular damages } \\
\text { - Dressing training; } \\
\text { - Autonomous movement. }\end{array}$ & Every day \\
\hline Table 3: Professional figures' interventions during the immediate post-surgical phase or preliminary outdoor phase. \\
\hline Psychologist & $\begin{array}{l}\text { - Help the patient to accept the stump and the } \\
\text { important changes of his body }\end{array}$ & If needed \\
\hline
\end{tabular}




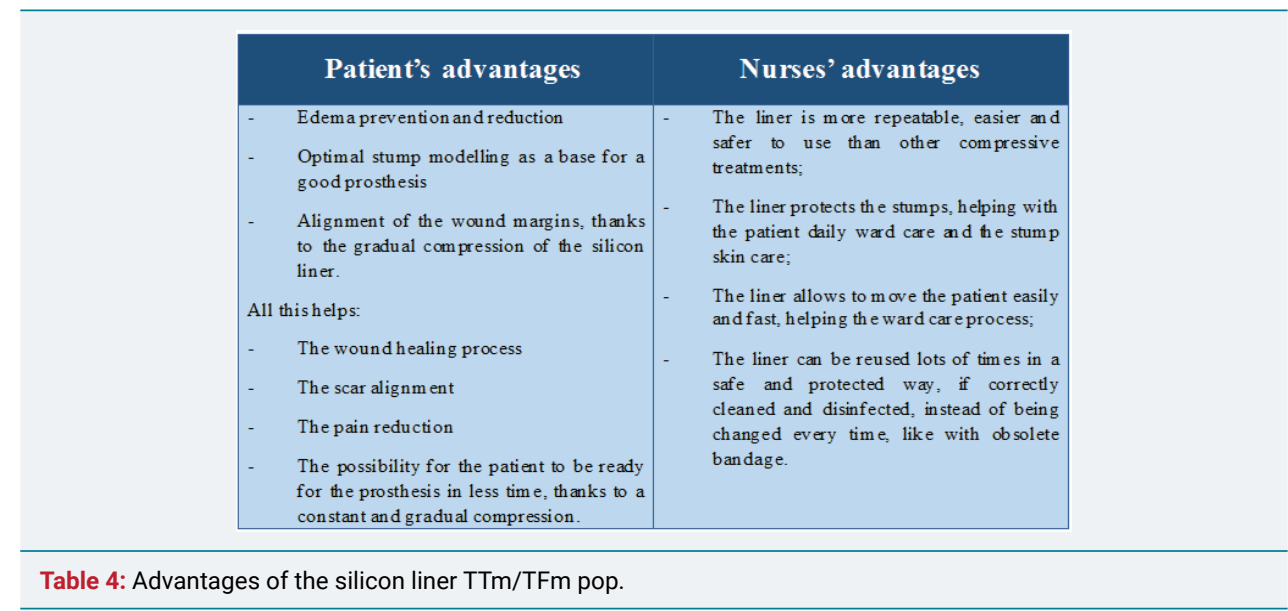

liner (silicon liner for trans-femoral prosthesis). This precise compression allows reducing or preventing efficaciously the post-surgical edemas. At the same time, the cuff use guarantees an early stump conformational stability in view of a successive prosthesis. As you can see from the literature, for the lower limb amputee, the stump control and modelling procedure is more important than the only prosthesis prescriptive appropriateness and manufacturing process. The liner is functionally better than the obsolete and unpractical elastic, modelling and anti-edema bandage. A silicon liner compressive therapy is already possible after 2-3 days from the operation, which means after the post-surgical drainage removal. This treatment is very effective because of the patient good compliance and the possibility of a better mobility.

Operative flow-chart of the silicon liner integrated management during the process of prosthesis stump preparation: integrated management of the stump edema.

The Operative flow-chart of the silicon liner integrated management is composed of 5 steps, which are as resumed in figure 2 .

- $\quad$ Step 1

Liner prescription (doctor-patient)

If the prosthesis use is indicated for our selected patient, his stump management starts immediately. The referring doctor sets and fixes the indications for the liner use in order to prepare the stump for the prosthesis. This step can happen during the indoor or outdoor phase, based on patient's conditions for the liner use in the surgery or rehabilitation unit. The silicon liner can be used only after the drainage removal (2-3 days after the amputation). This cut-off is in line with the established protocol timing for the liner introduction (at most within 5-10 days post-surgical intervention).

- $\quad$ Step 2

Integrated management for the liner choice and for the treated stump monitoring process (doctor-orthotic technician- patient) (Figure 3).

The protocol expect that the silicon liner is worn twice a day, in the morning and in the afternoon, for an increasing number of hours. The referring doctor after the first evaluation has to set a "Liner use timing table" (Table 5), where the hypothetical liner application and removal timing is defined. This data will be reported on the "Edema reduction table", that will be filled out daily by the ward nurses, with liner use timing, notes and signature, by the referring doctor who will report the stump cyrtometry, and by the orthotic technician that will also report the liner size.

- $\quad$ Step 3

Silicon liner application and removal procedure (doctor-orthotic technician- nurse) 


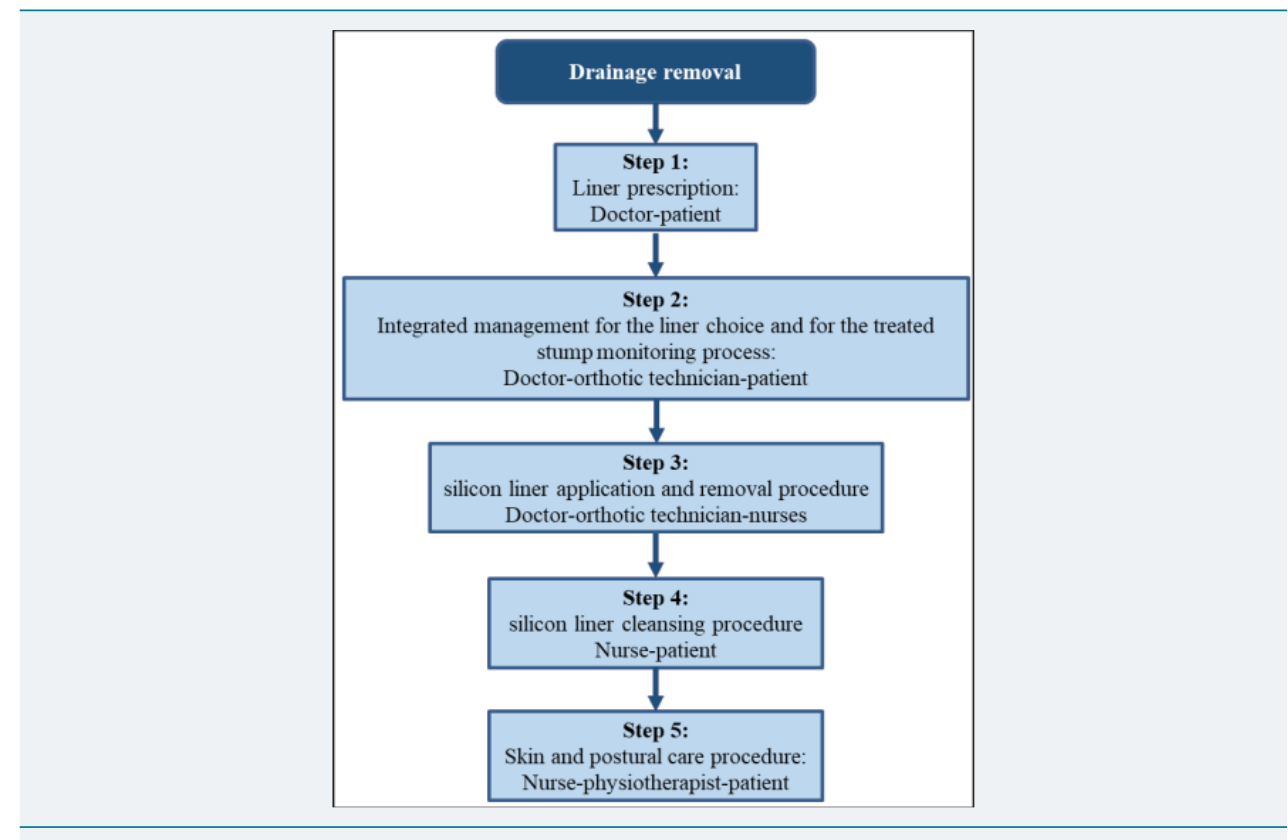

Figure 2: Procedural steps of the in-between phase.

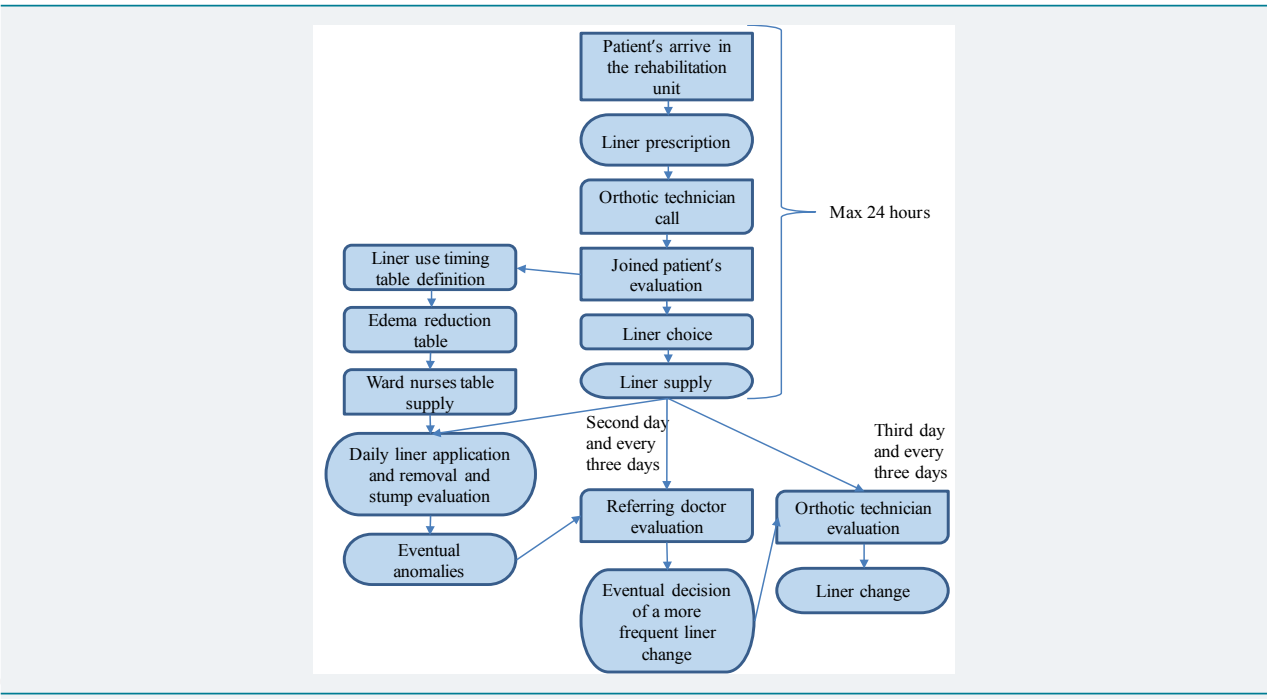

Figure 3: Integrated management for the liner choice and for the treated stump monitoring process flow-chart.

\begin{tabular}{|c|c|c|c|}
\hline Day & Hourly objective in the morning & Hourly ob jective in the afternoon & Total \\
\hline $1^{\text {st }}$ & 1 hour & 1 hour & 2 hours \\
\hline $2^{\text {nd }}$ & 2 hours & 2 hours & 4 hours \\
\hline $3^{\text {rd }}$ & 2 hours & 2 hours & 4 hours \\
\hline $4^{\text {th }}$ & 3 hours & 3 hours & 6 hours \\
\hline $5^{\text {th }}$ & 3 hours & 3 hours & 6 hours \\
\hline $6^{\text {th }}$ & 4 hours & 4 hours & 8 hours \\
\hline $7^{\text {th }}$ & 4 hours & 4 hours & 8 hours \\
\hline $8^{\text {th }}$ & 4 hours & 4 hours & 8 hours \\
\hline $9^{\text {th }}$ & 5 hours & 5 hours & 10 hours \\
\hline $10^{\text {th }}$ & 5 hours & 5 hours & 10 hours \\
\hline $11^{\text {th }}$ & 5 hours & 5 hours & 10 hours \\
\hline $12^{\text {th }}$ & 6 hours & 6 hours & 12 hours \\
\hline $13^{\text {th }}$ & 6 hours & 6 hours & 12 hours \\
\hline $14^{\text {th }}$ & 6 hours & 6 hours & 12 hours \\
\hline $15^{\text {th }}$ & 6 hours & 6 hours & 12 hours \\
\hline
\end{tabular}

Table 5: Liner use timing table. 
Every day, twice a day, the silicon liner must be applicated and removed, in order to obtain the best edema reduction process. Every phase of this process is accurately described in the tables 6-8.

- $\quad$ Step 4

\section{Silicon liner cleansing procedure (nurse-patient)}

When the patient is taken charge of, the ward care-giver is informed and/or taught how to accurately cleanse the patient's silicon liner. To prepare it to the first use and after every next use, the ward staff will cleanse the silicon liner accurately, always using protective gloves during the procedure.

\section{- $\quad$ Step 5}

Skin and postural care procedure (nurse-physiotherapist-patient)

To guarantee a correct skin and postural care to the patient, it's important to have an intense information exchange between the nurses and the physiotherapists, as well as an accurate attention to the stump care.

\section{Team work organization}

During this transitional phase the main team figures that participate at the interventions are the referring doctor, the orthotic technician and the ward nurses. Their main task specific interventions are resumed in the table 9 . We specify again that according to the timing characteristics of this phase, the referring doctor can be the surgeon, if the modelling phase starts when the patient's still in the surgical unit, or a rehabilitative physician, if the patient is already transferred to the rehabilitation unit.

\section{Indoor phase}

The Indoor phase starts when the patient arrives to a specialized rehabilitation unit, according to the suitability criteria for patient's transfer. This phase starts indicatively from the $6^{\text {th }}$ to the $9^{\text {th }}$ day after the surgical operation. The Indoor phase is the rehabilitative phase of our protocol: the patient could start a first standard rehabilitative intervention during the outdoor phase, but in this phase the rehabilitative interventions became individual and designed according to patient's needs. The main aims of this phase are:

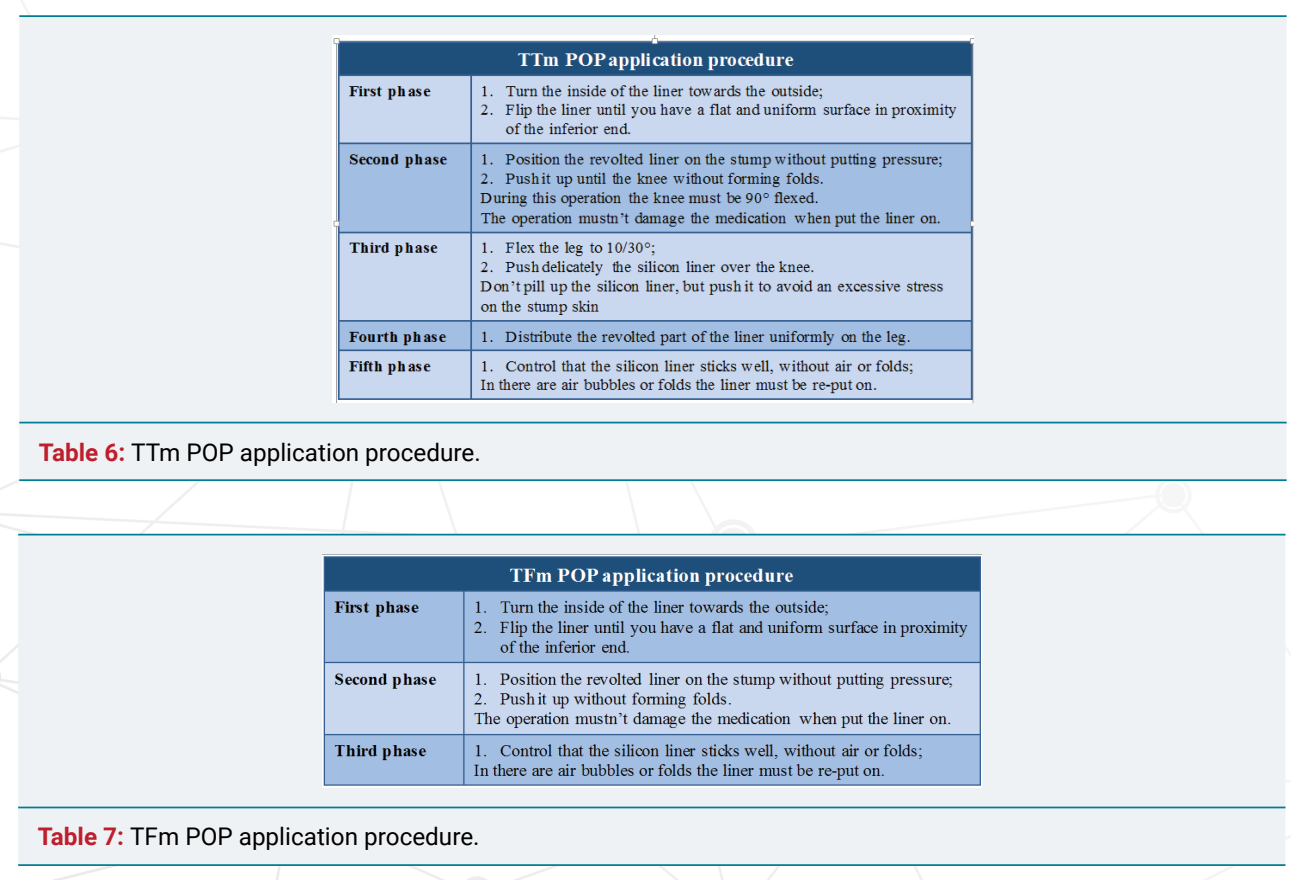




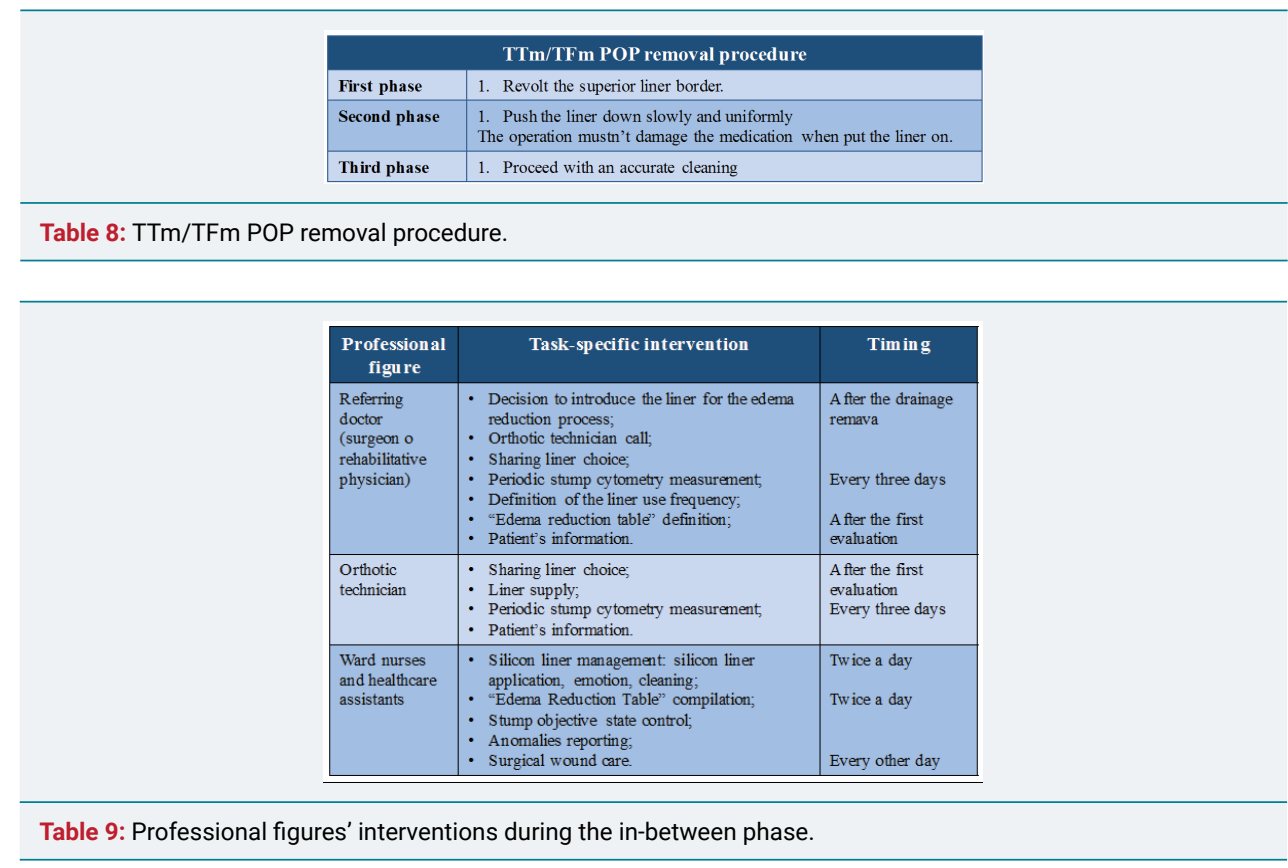

1. Stump preparation process: which continues or starts, if not started in the surgical unit;

2. Task-specific rehabilitative course: which continues or starts, if not started in the surgical unit;

3. Prosthesis manufacturing process: after the referring doctor and the orthotic technician prosthesis design, the first prosthesis, also called provisory prosthesis, is created;

4. Prosthesis rehabilitative program: the patient starts a pre-prosthesis rehabilitative program in prevision to the prosthesis use.

This phase can be divided in 2 sub-phases, with different aims and interventions: a pre-prosthesis and a post-prosthesis phase. Every phase is accurately described in a document called PRIA or "Amputee Integrated Rehabilitative Project". The PRIA of our TRIA-MF protocol mentiones a:

1. Functional outcome: the envisage outcome with the timing of the complete process: this time-course is generally between 14 to 24 days after the ward entrance.

2. Individual rehabilitative pre-prosthesis project: it defines the physiotherapy short term goals. These goals will be reached with patient's integrated management. The timing of this project is about $7 / 12$ days from the ward acceptance.

a. Individual rehabilitative pre-prosthesis program: it has the aim to delineate and expose to the physiotherapist the specific-task rehabilitative treatment operative plan. This plan was hypothesized during the take in charge of patient's integrated management during the pre-prosthesis phase.

b. Ward rehabilitative pre-prosthesis project: it contains the targets that must be reached by the different professional figures in the different professional ambits for the patient's integrated management of the pre-prosthesis phase.

3. Individual rehabilitative post-prosthesis project: it contains the physiotherapy mid-term goals. These goals are conditioned by the time of acquisition of the prosthesis during hospitalization in the ward. The timing of this project is about $7 / 12$ days from the ward entrance. 
a. Individual rehabilitative post-prosthesis program: it is necessary to delineate and expose the physiotherapist the supposed individual task-specific rehabilitative treatment in the integrated-management during the post-prosthesis phase.

b. Ward rehabilitative post-prosthesis project: it contains the targets that must be reached by the different professional figures in the different professional ambits for the patient's integrated management of the post-prosthesis phase.

\section{Study design and evaluation procedure}

In line with the INDOOR phase of the TRIA-MF protocol (lasting between 24 and 26 days), the design of our study has been outlined (Figure 4):

- $\quad$ Time T0: the patient is received in the Department by the multidisciplinary team (physiatrist, nurse, physiotherapist) and placed in his hospital room. The referring physician of the Rehabilitation Unit submits the patient to an anamnestic, clinical and functional evaluation by drawing up:

a. "Documentation file for the management of the lower limb amputation stump" and with it the "Edema Reduction Table" with attached and in a time-related manner the "Photographic documentation file;

b. PRIA (Integrated Rehabilitation Project of the amputee) with consensual delineation of the areas of shared intervention or drafting of the rehabilitation project of the Department;

c. VAS and Barthel evaluation scales;

d. Proceeding with the evaluation of the cirtometry at the time T0 of the amputation stump.

During the drafting of the PRIA (day of the arrival of recruited patient in the Rehabilitation Unit) the physiatrist defines all the professional figures of the team involved in the integrated management of the amputated patient; likewise, the referring physiatrist defines the objectives, the work program and the timing of the intervention of each professional figure of the team involved. In line with the established medical indications, the ward nurse and her staff welcome the patient into the room, collecting vital parameters and anamnesis; if possible they assist the evaluation, by the Referring

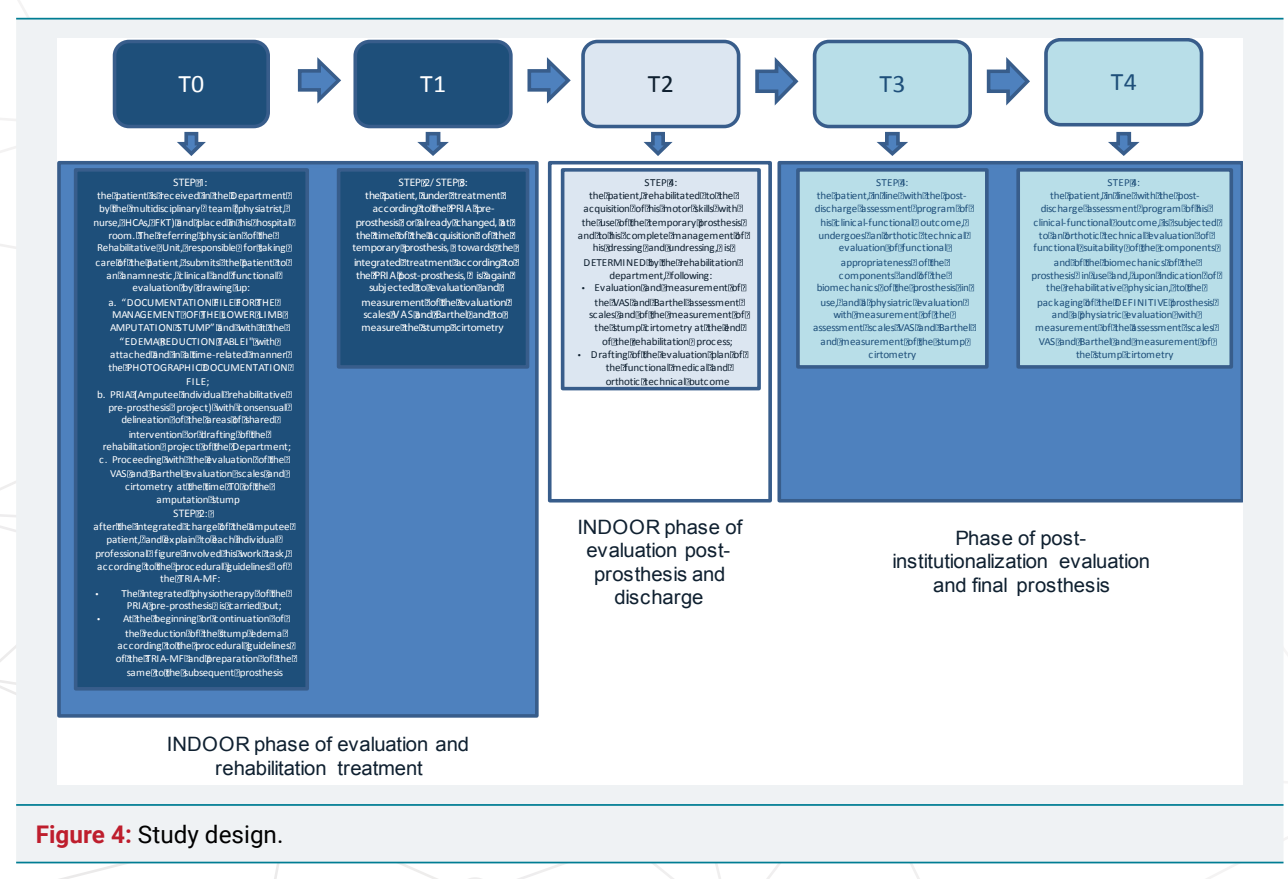


Physician, of the amputated patient with the drafting of the PRIA and the outline of the intervention steps to be implemented. In a shared way with the rest of the team, the physiotherapist takes care of the patient at the time T0 (entry of the patient in the Operative Unit), presents himself, exposes all the steps of his intervention according to the PRIA drawn up and subjects the patient amputated to a first functional physiotherapeutic evaluation with subsequent start of rehabilitation treatment. In line with the PRIA, the occupational therapist is involved in the management of the amputated patient between the fifth and tenth day of hospitalization. Upon indication of the clinical referent of the Department and if foreseen in the PRIA, the psychologist can be involved in the integrated management of the patient if requested by himself. The orthopedic technician is contacted by telephone by the Referring Physician of the Department of Rehabilitation and informed of the day of entry of the amputee patient (potentially already evaluated by the Orthopedic Technician in the Department of Surgery from which the patient recruited comes from); in line with the indication of the referring physiatrist, the orthopedic technician will proceed, at time T0, to measure the cirtometry of the patient's amputation stump, providing it with the POP preparation liner.

- Time T1: 10 days after entry into the Rehabilitation Unit, each patient in the sample is subjected to the same clinical-functional evaluation performed at the time T0 with measurement of the VAS, Barthel and cirtometry of the amputation stump.

- Time T2: 24-26 days after entry into the Rehabilitation Unit completed the pre-prosthetic rehabilitation and post-prosthesis procedure (after the acquisition of the temporary prosthesis) according to the PRIA prepared, each patient was again subjected to the measurement of the VAS scale, Barthel scale and cirrhometry of the amputation stump; in line with the subsequent evaluation phase of the results as per step 4 of the TRIA-MF protocol, the patient receives the discharge letter with the description of all the re-evaluation dates by the physiatrist (evaluation of the clinicalfunctional status of the abutment of amputation, motor performances achieved by the patient and functional appropriateness of the temporary prosthesis acquired) and by the orthopedic technician (evaluation of the technical-functional appropriateness of the components of the temporary prosthesis in use).

- Time T3: 1 month after discharge from the rehabilitation department, and in line with the timing of evaluation of the functional outcome according to the TRIAMF protocol, each patient of the study undergoes a reassessment of the technicalfunctional appropriateness of the components of the temporary prosthesis in use and a functional physiatric evaluation with measurement of the VAS, Barthel and cirtometry scales of the amputation stump.

- Time T4: 6 months after discharge from the rehabilitation department and in line with the timing of evaluation of the functional outcome according to the TRIA-MF protocol, each patient of the sample was subjected to a functional physiatric re-evaluation with measurement of the VAS scale, Barthel and of the cirtometry of the amputation stump; in this context and in line with the regional prescriptive guidelines, the physiatrist physician has prescribed and subsequently packaged the final prosthesis; in line with this indication, the orthopedic technician, after evaluating the technical and functional adequacy of the components of the existing temporary prosthesis proceeds with the acquisition of a new plaster cast of the amputation abutment, subsequent assembly of the final prosthesis and delivery of the same to the patient amputee.

\section{PRIA (Amputee Integrated Rehabilitation Project)}

Once the PRIA pre-prosthesis and post-prosthesis has been drafted, each team figure proceeds with the implementation of task-specific tasks in line with the TRIAMF protocol. In particular: 
Physiatrist: During the drafting of the PRIA (day of taking charge of the patient in the Rehabilitation Unit), the Physiatrist Doctor will share with all the staff of the department the objectives, the work schedule and their timing of intervention on the patient from the day of entry to the day of potential acquisition of the prosthesis previously designed in collaboration with the orthopedic technician.

Nurse: Upon arrival of the patient amputated in the Department, the nurse receives and manages the patient in the room as follows:

- control of vital parameters;

- skin care of the amputation stump;

- every other day, the nursing staff will supervise the surgical wound of the amputation stump, reporting daily on the nursing diary the evolutionary state of the patient; in line with the TRIA-MF protocol, the departmental nursing staff will provide the hygiene and sharing of the temporal management of the POP liner with predefined measurement of the modification of the stump edema that will be noted daily on the edema reduction table;

- postural care.

\section{Physiotherapist}

In a shared manner with the rest of the team, the physiotherapist accepts the amputated patient in his/her hospital at the time T0 (entry of the patient in the Department), presenting himself, outlining the same type and timetable of circadian rehabilitative intervention established by PRIA drawn up by the Referring doctor and proceeding with a first functional physiotherapy evaluation of the patient. Inspired by the PRIA established by the Referring Physician, proceeds with the implementation of the Individual Pre-Prosthetic Rehabilitation Program, according to the following steps outlined in a task-related manner and in relation to the type of patient's impairment; the Doctor will choose among the listed items those appropriate to time management as well as functional of the patient:

- diaphragmatic and bronchial respiratory physiotherapy;

- global articular passive/active mobilization of upper and lower limbs, paying particular attention to the amputation stump state;

- muscular reinforcement of both lower limbs, with isometric and isotonic exercises;

- electrostimulation by using rectangular waves, of the vastus medialis and lateralis, and the gluteus of the amputated limb; it is important to remember that this device can be applied if the skin is whole only;

- introduction and training of the silicon liner use in each patient recruited;

- application of decompressive muscular neurotaping on the anterior or posterior stump muscles; it is important to remember that this device can be applied if the skin is whole only;

- protrophic massage of the lower limb muscles;

- connective massage for the surgical scar's disconnection from the lower tissues, by giving an exteroceptive afferent stimulation to the stump;

- training of the postural passages and positional transfers, thanks to exercises of proprioceptive control and gridles fixation; 
- $\quad$ feedback and feedforward proprioceptive exercises for the trunk and gridles control to maintain the postures;

- feedback and feedforward proprioceptive exercises for the orthostatic control of the unit trunk-pelvis-heal lower limb with the help of:

o Assistance;

o Forearm walker;

o Roller with two tops and two rowels;

o Roller with four rowels;

o Articulated roller with two tops and two rowels;

o Two crutches;

- deambulation training with the help of:

- Assistance;

- $\quad$ Forearm walker;

_ $\quad$ Roller with two tops and two rowels;

- $\quad$ Roller with four rowels;

- $\quad$ Articulated roller with two tops and two rowels;

- $\quad$ Two crutches;

- $\quad$ Parallel bars.

In tables 10,11 we want to summarize the dedication (yes) or abstention (no) from the wide range of rehabilitation objectives and the corresponding PRIA preprosthesis program drawn up by the physiatrist for each patient upon entry into the Rehabilitation Unit.

Once the maximum degree of amination of the amputation stump is reached and the maximum degree of resorption of the stump edema, the referent physiatrist outlines the contents and initiates the so-called PRIA post-prosthetic phase. This phase of the PRIA consists of the design and acquisition of the prosthesis for our amputee patient and the drafting of a project and rehabilitation treatment program shared with the reference physiotherapist (time of implementation of the path on average between 7-12 days from entry in the Rehabilitation Unit). At this stage, shared goals include:

- training in the care and dressing / undressing in bed of the packaged prosthesis;

- control training in fixation of the tracks and trunk in the process of first vertical positioning on the spot with prosthesis, taking care of all the potential payments in the sequential phases of transition from sitting position to standing position and vice versa and outlining immediately the type of device support necessary to guarantee patient's maintenance of the orthostasis in place;

- $\quad$ optimization of the orthostatic postural structure of the trunk-pelvis unithealthy by using the acquired lower limb prosthesis;

- $\quad$ conditioning to proprioceptive control of the orthostatic load in alternating distribution before and equal distribution after between healthy and contralateral lower limb, supported by the use of the individualized aid chosen for the patient; 


\begin{tabular}{|c|c|c|c|c|c|c|c|c|c|c|c|c|}
\hline $\begin{array}{l}\text { Rehabilitative } \\
\text { preprosthesis project }\end{array}$ & A.P. & C.G. & F.A. & F.G.B. & G.V. & L.S. & M.A. & M.w. & P.B. & P.MR. & S.A. & V.M. \\
\hline Respiatory physiotherapy. & No & No & No & No & No & No & No & No & No & No & No & No \\
\hline Global articular mobilization & Yes & Yes & Yes & Yes & Yes & Yes & Yes & Yes & Yes & Yes & Yes & Yes \\
\hline Muscular reinforcement & Yes & Yes & Yes & Yes & Yes & Yes & Yes & Yes & Yes & Yes & Yes & Yes \\
\hline Electrostimulation & Yes & Yes & Yes & Yes & Yes & Yes & Yes & Yes & Yes & Yes & Yes & Yes \\
\hline $\begin{array}{l}\text { Introduction and training of the silicon } \\
\text { liner use for the patient. }\end{array}$ & Yes & Yes & Yes & Yes & Yes & Yes & Yes & Yes & Yes & Yes & Yes & Yes \\
\hline $\begin{array}{l}\text { Application of decompressive muscular } \\
\text { neurotaping }\end{array}$ & No & No & No & Yes & No & Yes & Yes & Yes & Yes & Yes & No & Yes \\
\hline Pro-trophic massage & No & No & No & Yes & No & Yes & Yes & Yes & Yes & Yes & No & Yes \\
\hline $\begin{array}{l}\text { Connective massage for the surgical } \\
\text { scar. }\end{array}$ & No & No & No & No & No & No & No & No & No & No & No & No \\
\hline $\begin{array}{l}\text { Training of the postural passages and } \\
\text { positional transfers }\end{array}$ & Yes & Yes & Yes & Yes & Yes & Yes & Yes & Yes & Yes & Yes & Yes & Yes \\
\hline $\begin{array}{l}\text { Proprioceptive exercises for posture } \\
\text { maintaining }\end{array}$ & Yes & Yes & Yes & Yes & Yes & Yes & Yes & Yes & Yes & Yes & Yes & Yes \\
\hline $\begin{array}{l}\text { Proprioceptive exercises for the } \\
\text { orthostatic control, with help }\end{array}$ & Yes & Yes & Yes & Yes & Yes & Yes & Yes & Yes & Yes & Yes & Yes & Yes \\
\hline Deambulation training with help & No & No & No & Yes & No & Yes & Yes & Yes & Yes & Yes & No & Yes \\
\hline Behavioural therapy & Yes & Yes & Yes & Yes & Yes & Yes & Yes & Yes & Yes & Yes & Yes & Yes \\
\hline Occupational therapy & Yes & Yes & Yes & Yes & Yes & Yes & Yes & Yes & Yes & Yes & Yes & Yes \\
\hline
\end{tabular}

Table 10: Patient participation to the PRIA pre-prosthesis project.

\begin{tabular}{|c|c|c|c|c|c|c|c|c|c|c|c|c|}
\hline $\begin{array}{l}\text { Rehabiltative } \\
\text { pre-prosthesis program }\end{array}$ & A.P. & C.G. & F. A. & F.G.B. & G.V. & LS. & M.A. & M.w. & P.B. & P.M.R. & S.A. & V.M. \\
\hline Respiratory rehabilitation & No & No & No & No & No & No & No & No & No & No & No & No \\
\hline Prevention of the myoarticular damages & Yes & Yes & Yes & Yes & Yes & Yes & Yes & Yes & Yes & Yes & Yes & Yes \\
\hline Muscular reinforcement & Yes & Yes & Yes & Yes & Yes & Yes & Yes & Yes & Yes & Yes & Yes & Yes \\
\hline Edema reduction & No & Yes & Yes & No & Yes & Yes & No & No & Yes & Yes & Yes & Yes \\
\hline $\begin{array}{l}\text { Improvement of the postural passages } \\
\text { and positional transfers }\end{array}$ & Yes & Yes & Yes & Yes & Yes & Yes & Yes & Yes & Yes & Yes & Yes & Yes \\
\hline $\begin{array}{l}\text { Facilitation and optimization of the } \\
\text { postural reaction control and posture } \\
\text { reaching }\end{array}$ & Yes & Yes & Yes & Yes & Yes & Yes & Yes & Yes & Yes & Yes & Yes & Yes \\
\hline Standing reconditioning & Yes & Yes & Yes & Yes & Yes & Yes & Yes & Yes & Yes & Yes & Yes & Yes \\
\hline Deambulation reconditioning & Yes & Yes & Yes & Yes & Yes & Yes & Yes & Yes & Yes & Yes & Yes & Yes \\
\hline $\begin{array}{l}\text { Gait training in prevision of the } \\
\text { prosthesis. }\end{array}$ & Yes & Yes & Yes & Yes & Yes & Yes & Yes & Yes & Yes & Yes & Yes & Yes \\
\hline $\begin{array}{l}\text { Behavioural training and occupational } \\
\text { training. }\end{array}$ & Yes & Yes & Yes & Yes & Yes & Yes & Yes & Yes & Yes & Yes & Yes & Yes \\
\hline Psychological help & Yes & Yes & Yes & Yes & Yes & Yes & Yes & Yes & Yes & Yes & Yes & Yes \\
\hline
\end{tabular}

Table 11: Patient participation to the individual rehabilitative pre-prosthesis program.

- first reconditioning to the alternate transfer of the orthodynamic load with the use of the prosthesis between the parallels, in front of the mirror (cognitive-behavioral training and visual feedback of reinforcement in the control of the orthodynamic posture of the trunk and pelvis) and with the constant verbal call and corrections imposed by the reference physiotherapist;

- reconditioning to the control of the out-parallel gait-cycle with the use of an aid (roller or crutches) with particular attention to the control in fixation and release of the basin during stance and swing phase of the step and integration of the global postural control with the fixation (stance) and retraction (for activation in progress of the pelvis starting from the prosthetic side and inertia for elastic return of the prosthesis in the second instance) of the prosthesis in adoption;

- constant inhibition of positional defects and/or control of global postural positioning in orthostasis and orthodynamic use of the prosthesis acquired;

- behavior training and occupational training;

- facilitation and guidance of the patient in the process of adaptation and acceptance of the prosthesis in adoption.

In tables 12,13 we want to summarize the dedication (yes) or abstention (no) from the wide range of rehabilitation objectives and the corresponding PRIA postprosthesis program drawn up by the physiatrist for each patient upon entry into the Rehabilitation Unit. 


\begin{tabular}{|l|l|l|l|l|l|l|l|l|l|l|l|l|l|l|}
\hline $\begin{array}{l}\text { Reh abilitative } \\
\text { post-prosth esis project }\end{array}$ & A.P. & C.G. & F.A. & F.G.B. & G.V. & L.S. & M.A. & M.W. & P.B. & P.M.R. & S.A. & V.M. \\
\hline Prosthesis cure and management & Yes & Yes & Yes & Yes & Yes & Yes & Yes & Yes & Yes & Yes & Yes & Yes \\
\hline Standing training with the prosthesis & Yes & Yes & Yes & Yes & Yes & Yes & Yes & Yes & Yes & Yes & Yes & Yes \\
\hline Optimization of the static posture & Yes & Yes & Yes & Yes & Yes & Yes & Yes & Yes & Yes & Yes & Yes & Yes \\
\hline Orthostatic load distribution & Yes & Yes & Yes & Yes & Yes & Yes & Yes & Yes & Yes & Yes & Yes & Yes \\
\hline $\begin{array}{l}\text { Orthodynamic alternate load transfert } \\
\text { whit prosthesis }\end{array}$ & Yes & Yes & Yes & Yes & Yes & Yes & Yes & Yes & Yes & Yes & Yes & Yes \\
\hline Gaittraining & Yes & Yes & Yes & Yes & Yes & Yes & Yes & Yes & Yes & Yes & Yes & Yes \\
\hline Global postural asset & Yes & Yes & Yes & Yes & Yes & Yes & Yes & Yes & Yes & Yes & Yes & Yes \\
\hline Behavoral and ocupational training & Yes & Yes & Yes & Yes & Yes & Yes & Yes & Yes & Yes & Yes & Yes & Yes \\
\hline Guide during acepting proces & yes & yes & yes & yes & yes & yes & yes & yes & yes & yes & yes & yes \\
\hline
\end{tabular}

Table 12: Patient participation to the PRIA post-prosthesis project.

\begin{tabular}{|c|c|c|c|c|c|c|c|c|c|c|c|c|}
\hline $\begin{array}{l}\text { Rehabifitative } \\
\text { post-prosthesis program }\end{array}$ & A.P. & c.G. & F. A. & F.G.B. & G.V. & L.S. & M.A. & M.w. & P.B. & P.M.R. & S.A. & v.M. \\
\hline Articular mobilization & Yes & Yes & Yes & Yes & Yes & Yes & Yes & Yes & Yes & Yes & Yes & Yes \\
\hline Muscular reinforcement & Yes & Yes & Yes & Yes & Yes & Yes & Yes & Yes & Yes & Yes & Yes & Yes \\
\hline Electrostimolation & Yes & Yes & Yes & Yes & Yes & Yes & Yes & Yes & Yes & Yes & Yes & Yes \\
\hline $\begin{array}{l}\text { Training of the postural passages and } \\
\text { transfers }\end{array}$ & Yes & Yes & Yes & Yes & Yes & Yes & Yes & Yes & Yes & Yes & Yes & Yes \\
\hline $\begin{array}{l}\text { Proprioceptive exercies of sitting } \\
\text { posture }\end{array}$ & Yes & Yes & Yes & Yes & Yes & Yes & Yes & Yes & Yes & Yes & Yes & Yes \\
\hline $\begin{array}{l}\text { Proproceptive exercises for the sitting } \\
\text { control with prosthesis }\end{array}$ & Yes & Yes & Yes & Yes & Yes & Yes & Yes & Yes & Yes & Yes & Yes & Yes \\
\hline $\begin{array}{l}\text { Proprioceptive exercises of sitting load } \\
\text { transfer }\end{array}$ & Yes & Yes & Yes & Yes & Yes & Yes & Yes & Yes & Yes & Yes & Yes & Yes \\
\hline $\begin{array}{l}\text { Proproceptive exercises standing } \\
\text { betwen paralel bars }\end{array}$ & Yes & Yes & Yes & Yes & Yes & Yes & Yes & Yes & Yes & Yes & Yes & Yes \\
\hline $\begin{array}{l}\text { Proprioceptive exercises of standing } \\
\text { load transfer }\end{array}$ & Yes & Yes & Yes & Yes & Yes & Yes & Yes & Yes & Yes & Yes & Yes & Yes \\
\hline Gait training between paralel bars & Yes & Yes & Yes & Yes & Yes & Yes & Yes & Yes & Yes & Yes & Yes & Yes \\
\hline Gait training out of paralel bars with aid & Yes & Yes & Yes & Yes & Yes & Yes & Yes & Yes & Yes & Yes & Yes & Yes \\
\hline Gait training with out outdoor & Yes & Yes & Yes & Yes & Yes & Yes & Yes & Yes & Yes & Yes & Yes & Yes \\
\hline Gait training on the stairs & Yes & Yes & Yes & Yes & Yes & Yes & Yes & Yes & Yes & Yes & Yes & Yes \\
\hline $\begin{array}{l}\text { Behavioural training and occupational } \\
\text { training for prosthesis and emergency } \\
\text { management }\end{array}$ & Yes & Yes & Yes & Yes & Yes & Yes & Yes & Yes & Yes & Yes & Yes & Yes \\
\hline $\begin{array}{l}\text { Behavioural tra ining and occupational } \\
\text { training for prosthesis } A D L\end{array}$ & Yes & Yes & Yes & Yes & Yes & Yes & Yes & Yes & Yes & Yes & Yes & Yes \\
\hline
\end{tabular}

\section{Occupational therapist}

In line with the PRIA, the OT is called in question between the 5th and 10th day of admission of the patient in the Rehabilitation Unit with the following functions:

- impairment-related review of praxic skills in care and management of dressing and undressing of the silicon liner and the prosthesis adopted;

- impairment-related review of praxic skills in the care and management of ADL and of personal care and targeted movements with the prosthesis;

- $\quad$ sharing with the nursing staff of the process of supervision and circadian facilitation of the praxic skills progressively acquired and the use of the prosthesis acquired.

\section{Psychologist}

If specifically requested by the patient a psychological support will be involved in the integrated management of our amputees. The psychologist has the function of:

- outline the pre-and post-morbid psychological and character profile of the patient;

- understand the patient's psychological processes influenced and subsequent to limb amputation;

- delineate a path of existential rehabilitation of the patient to the new condition of life following the amputation, necessary to ensure a satisfactory future life at the same time. 


\section{Orthopedic technician}

The orthopedic technician is contacted by telephone by the reference Doctor of the Rehabilitation Unit and informed of the date of entry of the amputee patient; on the indication of the PRIA referring physician and upon entry into the patient's ward (time T0) the orthosis technician will proceed to:

- bed supervision of the patient's amputation abutment;

- if not already implemented in the outdoor phase, specific supply of the silicone edema reduction liner;

- if not already implemented in the outdoor phase, sharing with the referring physician the degree of compromise of the patient on which to define the belonging of the same to a specific mobility class ("MOBIS" - K0 / K4 Code Level);

- based on the defined K level, design of the type of prosthesis to be packaged;

- every 3 days to the supervision of the amputation abutment, of the cirtometry of the abutment and possible change of the silicone liner in relation to the reduction of the edema of the abutment found.

\section{Outcome measures}

Outcome measures considered valid for the clinical-functional and temporal monitoring of each patient's response to the TRIA-MF protocol proposed by us on the recruited patients are the following:

- $\quad$ Functional items

o Pain measured with analog VAS scale (0-10);

o Barthel Index;

o $\quad$ Cirtometry of the amputation stump (at $4-8 \mathrm{~cm}$ from the edge of the stump) measured in $\mathrm{cm}$;

- $\quad$ Temporal items

o Inter-time expressed in days between date of day of amputation (A) and date of first prosthesis (temporary prosthesis) (TP) under institutionalization;

o Inter-time expressed in days between date of first prosthesis (TP) and date of definitive prosthesis (definitive prosthesis) (DP);

o Duration of hospitalization in Rehabilitative Unit (expressed in days from the time the patient enters the ward).

\section{Statistical analysis}

Statistical analysis was made using the statistical software SPSS (version 22). Timerelated differences between our clinical variables was performed using a parametric one-sample t-test. The Pearson Correlation Coefficient (PCC) was also used to realize an inter-time (from time T0 to time T4) comparative analysis between our temporal data and clinical data. The significance level was set to $\mathrm{p}<0.05$.

\section{Results}

\section{Temporal data}

Patients of our sample, at the end of their hospitalization, highlight a significant modification of the temporal data at 1 month and 6 months from their hospital discharge. In particular we observed that all patients showed: 
- $\quad$ a mean inter-time expressed in days between date of amputation (A) and date of first prosthesis acquisition (temporary prosthesis) (TP) during hospitalization of $55,5+/-36,07$ days; in 6 of 12 patients of our sample affected by a not-complicated surgical wound, the intertime was $25.6+/-11.48$ days; in 6 patients out of 12 affected by a complicated surgical wound the intertime was $85.3+/-24.3$ days; all patients acquired a temporary prosthesis, starting from the rehabilitative recovery, after 9,08 + - 3,96 days;

- a mean inter-time expressed in days between date of first prosthesis acquisition (TP) and date of definitive prosthesis acquisition (definitive prosthesis) (DP) of 180 days (official minimal temporal trend for the definitive prosthesis acquisition;

- a mean duration of hospitalization in the Rehabilitative Unit (expressed in days starting from patient's hospitalization) of 23,5 +/- 2,9 days (gold standard of an official recovery duration of amputees patients in an Italian Rehabilitative Unit)

\section{Functional results}

In line with our study design, a simple clinical examination was performed before, at the end of each patient's clinical and rehabilitative recovery and after the hospitalization. In tables 14-16 mean values and DS of each clinical outcome measure are summarized.

\section{- $\quad$ Barthel Index}

A statistical significant increase of the Barthel Index value was observed in all patients recruited in this study proceeding from time T0 to time T4 (Figure 5).

As defined by the parametric one-sample t-test, a statistical significant trend was observed in all evaluable intertime of this study: a statistical significant trend was observed proceeding from time T0 to $\mathrm{T} 1[\mathrm{t}(11)=-7,50$ with $\mathrm{p}<.0001]$, from $\mathrm{T} 0$ to T2 $[\mathrm{t}(11)=-19$ with $\mathrm{p}<.0001]$, from T0 to T3 [t(11) $=-17,06$ with $\mathrm{p}<.0001]$, from T0 to T4 $[\mathrm{t}(11)=-22,82$ with $\mathrm{p}<.0001]$, from $\mathrm{T} 1$ to $\mathrm{T} 2$ [t(11) $=-11$ with $\mathrm{p}<.0001]$, from $\mathrm{T} 1$ to T3 [ $\mathrm{t}(11)=-23,45$ with $\mathrm{p}<.0001]$, from $\mathrm{T} 1$ to $\mathrm{T} 4$ [ $\mathrm{t}(11)=-11,82$ with $\mathrm{p}<.0001]$, from $\mathrm{T} 2$ to T3 $[\mathrm{t}(11)=-3,75$ with $\mathrm{p}<.005]$, from $\mathrm{T} 2$ to $\mathrm{T} 4$ [t(11) $=-4,55$ with $\mathrm{p}<.001]$, from T3 to $\mathrm{T} 4[\mathrm{t}(11)=-2,24$ with $\mathrm{p}<.05]$.

\section{- $\quad$ VAS scale}

A statistical significant decrease of the VAS scale was observed in all patients recruited in this study proceeding from time T0 to time T4 (Figure 6).

As defined by the parametric one-sample $t$-test, a statistical significant trend was observed in all evaluable intertime of this study: a statistical significant trend was observed proceeding from time $\mathrm{T} 0$ to $\mathrm{T} 1[\mathrm{t}(11)=3,63$ with $\mathrm{p}<.005]$, from $\mathrm{T} 0$ to $\mathrm{T} 2$ $[\mathrm{t}(11)=5,26$ with $\mathrm{p}<.0001]$, from T0 to T3 [t(11) $=5,3$ with $\mathrm{p}<.0001]$, from T0 to T4 $[\mathrm{t}(11)=5,25$ with $\mathrm{p}<.0001]$, from $\mathrm{T} 1$ to $\mathrm{T} 2$ [ $\mathrm{t}(11)=3,92$ with $\mathrm{p}<.005]$, from T1 to T3 $[\mathrm{t}(11)=3,92$ with $\mathrm{p}<.005]$, from $\mathrm{T} 1$ to $\mathrm{T} 4[\mathrm{t}(11)=4,14$ with $\mathrm{p}<.005]$, from T2 to T3 [ $\mathrm{t}(11)=2,24$ with $\mathrm{p}<.05]$, from T2 to T4 [t(11) = 2,6 with $\mathrm{p}<.05]$, from T3 to T4 [t(11) $=1,8$ with $\mathrm{p}(\mathrm{ns})]$.

- $\quad$ Cirtometry of the amputation stump

A statistical significant decrease of the cirtometry of the amputation stump (expressed in $\mathrm{cm}$ ) was observed in all patients recruited in this study proceeding from time T0 to time T4 (Figure 7).

As defined by the parametric one-sample $t$-test, a statistical significant trend was observed in all evaluable intertime of this study: a statistical significant trend was 


\begin{tabular}{|c|ccccc|}
\hline & \multicolumn{5}{|c|}{ Barthel Index } \\
\cline { 1 - 2 } & T0 & T1 & T2 & T3 & T4 \\
\cline { 1 - 2 } Mean value & 44,1 & 57,5 & 75,8 & 82,5 & 89,5 \\
\cline { 1 - 1 } SD (+/-) & 7,33 & 9,88 & 70,62 & 11,38 & 8,9 \\
\hline
\end{tabular}

\begin{tabular}{|c|ccccc|}
\hline & \multicolumn{5}{|c|}{ VAS scale } \\
\cline { 1 - 5 } & T0 & T1 & T2 & T3 & T4 \\
\cline { 1 - 5 } Mean value & 5 & 3,1 & 1,4 & 0,8 & 0,5 \\
\cline { 1 - 5 } SD (+/-) & 3,33 & 2,32 & 1,62 & 1,11 & 0,67 \\
\hline
\end{tabular}

Table 15: Mean values and SD of time-related VAS scale.

\begin{tabular}{|c|c|c|c|c|c|}
\hline & \multicolumn{5}{|c|}{ Cirtometry of the amputation stump } \\
\hline & T0 & $\mathrm{T} 1$ & $\mathrm{~T} 2$ & $\mathrm{~T} 3$ & $\mathrm{~T} 4$ \\
\hline Mean value & 45,79 & 43,7 & 42,33 & 42,33 & 41,25 \\
\hline $\mathrm{SD}(+/-)$ & 7,25 & 7,36 & 7,19 & 7,22 & 7,93 \\
\hline
\end{tabular}

Table 16: Mean values and SD of time-related cirtometry of amputation stump.

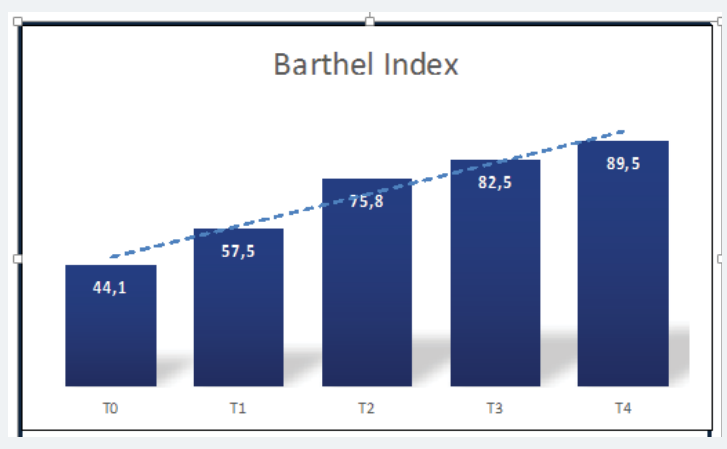

Figure 5: Barthel Index time-related trend proceeding from T0-T4.

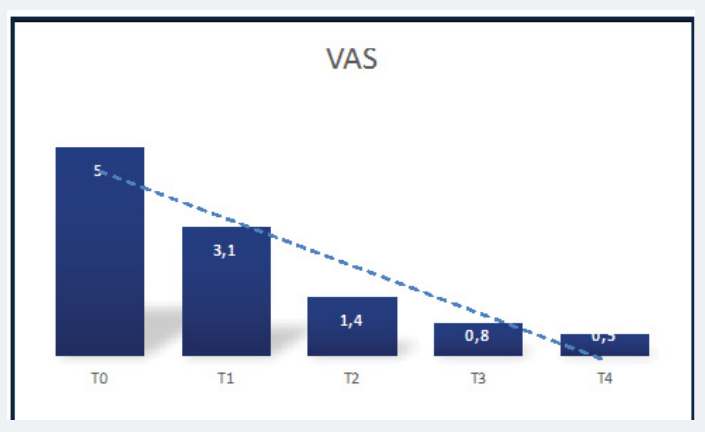

Figure 6: VAS time-related trend proceeding from T0-T4. 


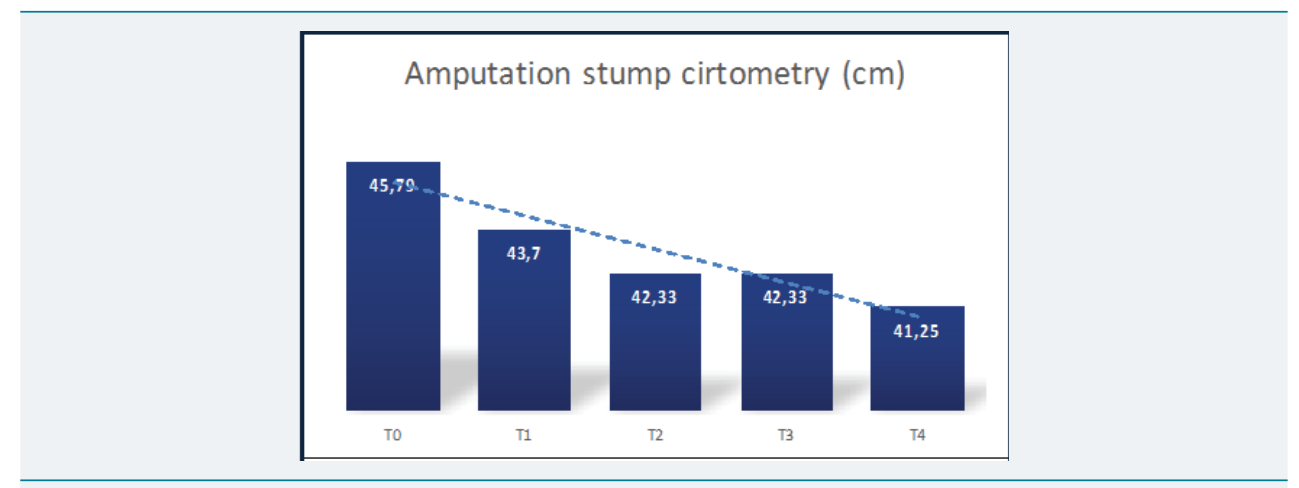

Figure 7: Amputation stump cirtometry time-related trend proceeding from T0-T4.

observed proceeding from time $\mathrm{T} 0$ to $\mathrm{T} 1[\mathrm{t}(11)=9,45$ with $\mathrm{p}<.0001]$, from $\mathrm{T} 0$ to $\mathrm{T} 2$ $[\mathrm{t}(11)=10,02$ with $\mathrm{p}<.0001]$, from T0 to T3 [t(11) = 10,92 with $\mathrm{p}<.0001]$, from T0 to $\mathrm{T} 4[\mathrm{t}(11)=9,65$ with $\mathrm{p}<.0001]$, from $\mathrm{T} 1$ to $\mathrm{T} 2[\mathrm{t}(11)=4,98$ with $\mathrm{p}<.0001]$, from $\mathrm{T} 1$ to $\mathrm{T} 3[\mathrm{t}(11)=5,25$ with $\mathrm{p}<.0001]$, from $\mathrm{T} 1$ to $\mathrm{T} 4$ [t(11) $=5,92$ with $\mathrm{p}<.0001]$, from T2 to $\mathrm{T} 3$ [ $\mathrm{t}(11)=0$ with $\mathrm{p}(\mathrm{ns})]$, from T2 to T4 [t(11) = 2,44 with $\mathrm{p}<.05]$, from T3 to T4 [t(11) $=2,6$ with $\mathrm{p}<.05]$.

- Comparative analysis of clinical data versus temporal data

In line with the aim, of this study we realized a comparative and time-related analysis between our clinical and temporal data by using the Pearson Correlation Coefficient. Particularly: we didn't observed a statistical significant correlation between the duration of the rehabilitative hospitalization and our clinical data; similarly no statistical significant correlation was observed between the amputation stump cirtometry time-related modification and our intertime data.

\section{Discussion}

In the management of the complexity profile of patients affected by non-traumatic lower limb amputation, it's important to have a real procedural algorithm regulating the organic and planned drafting of a global loading of the prosthetic amputee patient. The history and the clinical experience teach us also in this case how the delineation of an integrated management strategy, in which every single professional knows exactly what, how and when to do, constitutes a modern interpretation key of correct treatment of the patient amputee. The aim of this study was to present to the reader the knowledge of the first real integrated or multiprofessional management tool of the amputee prosthesisable patient that with reference to its structure and author we wanted to indicate with the acronym TRIA-MF. For those who have had the opportunity to put into practice the good-governance process of the amputee patient, mentioned in the TRIA-MF protocol, an element of fundamental importance and often not well defined in the work of a professional's department immediately leaps to mind: the effective communication. During all stages of patient management, we know how effective communication between individual professionals in the group can be successfull for a medical team. But this cannot be left at the mercy of the case but rather regulated by well-defined operational steps in which everyone knows both temporally and operationally to act for competence and knowledge of their actions. Starting from an accurate illustration of the content of this guideline and how and when it can be applied in the often complex and expensive management of a selected sample of 12 patients with prosthesis lower limb amputation and treated at the Rehabilitation Department of the Clinical Institute City of Brescia in the period between January 2017 and January 2018, we have been able to highlight its clear scientific-operational value. Operational tool of absolute versatility and ease of application, the TRIA-MF protocol shows to provide the operator with all the information necessary for the correct management of the patient in the amputee; the tool is clear and relevant in its structure and certainly 
very precise and innovative in the delineation of the professional-operational profile of every single operator that is mentioned. Starting from an accurate preliminary training of all the professional figures who are actively involved in the management of the amputated patient, with clear delineation of all the steps that regulate the operation, the TRIA-MF protocol places itself at the attention of the rehabilitation world as one a tool able to guarantee a high impact on the quality and safety of the work of the Department personnel and the appropriate management of our amputee. When an instrument appears to be able to outline all the operational steps of the Department staff as well as the specificity of action of the individual in each stage of treatment of the amputee, it can only be defined as a protocol with high methodological potential of re-producibility, sensitivity and specificity. With the following study, we were able to conduct an observational study of efficacy on a well-selected sample of patients affected by amputation outcomes and admitted according to specific inclusion criteria (or transferability) to the INDOOR phase of rehabilitation and integrated prosthesis at the Department of Rehabilitation of the City of Brescia. Starting from a correct and shared treatment of the patient, a linear management of the stump edema and the preand post-prosthetic rehabilitation path of the amputee patient, we were able to demonstrate, first of all, a statistically significant improvement in the profile of progressive patient autonomy expressed by the Barthel scale. The process of integration of 2 professional figures of basic importance (mentioned and well defined in the protocol) such as the physiotherapist on the one hand and the occupational therapist on the other, have granted our patients the possibility of recovering both motor skills and skill management praxis aimed at the autonomous management of the positional passages, of the path and of common daily life activities and personal care. The critical point of the IN-BETWEEN and INDOOR phase of the protocol results in the correct management and preparation of the amputation stump through a perfect integration between monitored reduction of the stump edema by means of a POP liner and proper rehabilitative management of the same. Thus, at the end of our study we were able to demonstrate the statistically significant reduction of the amputation stump cirtometry from T0 to T4 (moment of definitive patient restoration), as an expression of a fluid and prompt preparation of the patient to the prosthesis use as well as demonstration of how even at a distance from the rehabilitative hospitalization a correct continuation of the treatment of the stump with liner and monitoring of patient's functional outcome may be associated with a further and future modification of the amputation stump. If it is true that the liner, as an exogenous mechanical stimulus, can influence in a pro-adaptive way the embodyment of the amputated patient and effectively modulate the central representation of the body schema with a direct impact on that neuroplasticity able to influence the pain threshold of our patient (measured with VAS scale), we have succeeded in demonstrating how its correct insertion in the IN-BETWEEN and INDOOR procedure of management of the stump edema may have statistically reduced the perception of limb ghost pain passing from T0 to T4. The clinical results described so far in the application of the integrated amputation management protocol demonstrate the evaluative and descriptive efficacy in terms of functional outcome of this new tool for coding the management, treatment and evaluation of the effectiveness of the patient's treatment. An accurate analysis of the temporal outcome, mentioned in our study, shows how a correct and appropriate temporal management of the amputee patient has conscientized us of: a. not to exceed on average the 23 days of hospitalization from entering the Department to the discharge of the patient equipped and trained for the use of the lower limb prosthesis; b. to subject all patients taken care of with specific pre-requisites mentioned in the protocol to a temporary prosthesis of the amputated limb on average not more than 9.08 days from the entrance; $c$. to conduct in real time all patients admitted and in line with the hospitalization duration for the amputees to a complete recovery of the path with prosthesis at the time of discharge from the Department; d. to stay in line with the 6 months of intertime between the TP and the DP prescription for all patients recruited 
and led to it, with invaluable impact on the optimization of the long-term economic management of the amputated patients. In a World Healthcare increasingly attentive to the costs of patient management and to the increasingly rigorous respect of the minimum and maximum admission times granted by type of patient admitted, the results obtained with our study highlight the strong respect profile that has been achieved to maintain maximum times of up to 23 days of hospitalization granted in the subacute rehabilitative management of the amputated patient. With this in mind, the socio-economic value of the TRIA-MF protocol is in place, capable of constituting in the next few years a real orientation to the economic dimension (budget and staff management) of the management of the amputee with the delineation of a potential cost optimization profile in patient's medium to long-term management. Nevertheless our clinical results, the comparative study with the temporal outcome data did not demonstrate a statistically significant correlation between the duration of the hospitalization and the improvement in the modulation of the stump edema as well as with the prosthesis intertime use. This apparently negative data represents a strong point of our study and above all of the TRIA-MF protocol, focusing the work on the amputated patient not only by the preparation of the edema but with the management of the whole profile of patient's high physical, clinical, psychological and social complexity; it represents a model of work and global and multi-professional management of the amputee patient with obvious repercussions on the optimization of patient's clinical and temporal management.

\section{Conclusion}

In the management of the complexity profile of patients affected by non-traumatic lower limb amputation, it's important to have a real procedural algorithm regulating the organic and planned drafting of a global loading of the prosthetic amputee patient.

Operational tool of absolute versatility and ease of application, the TRIA-MF protocol shows to provide the operator with all the information necessary for the correct management of the patient in the amputee; the tool is clear and relevant in its structure and certainly very precise and innovative in the delineation of the professional-operational profile of every single operator that is mentioned.

When an instrument appears to be able to outline all the operational steps of the Department staff as well as the specificity of action of the individual in each stage of treatment of the amputee, it can only be defined as a protocol with high methodological potential of re-producibility, sensitivity and specificity.

The clinical results described so far in the application of the integrated amputation management protocol demonstrate the evaluative and descriptive efficacy in terms of functional outcome of this new tool for coding the management, treatment and evaluation of the effectiveness of the patient's treatment.

In a World Healthcare increasingly attentive to the costs of patient management and to the increasingly rigorous respect of the minimum and maximum admission times granted by type of patient admitted, the results obtained with our study highlight the strong respect profile that has been achieved to maintain maximum times of up to 23 days granted in the subacute rehabilitative management of the amputated patient.

The socio-economic value of the TRIA-MF protocol is in place, capable of constituting in the next few years a real orientation to the economic dimension (budget and staff management) of the management of the amputee with the delineation of a potential cost optimization profile in patient's medium to long-term management.

\section{References}

1. Ippolito E, Flaviani L, Belcaro G. Amputazione degli arti inferiori nelle arteriopatie periferiche. Edizioni Minerva Medica, 2005; Ref.: https://goo.gl/j1zT7d 
2. De Ciechi R. Ausili per persone adulte ed anziane amputate di arto inferiore. Corso di perfezionamento. Fondazione Don Carlo Gnocchi, 2009/2010. Ref.: https://goo.gl/nRLXoy

3. Zaniolo O. Costi del diabete in Italia. Farmaeconomia e percorsi terapeutici, 2009. Ref.: https://goo.gl/ketA1M

4. Geertzen J1, van der Linde H2, Rosenbrand K3, Conradi M4, Deckers J, et al. Dutch evidence-based guidelines for amputation and prosthetic of lower extremity: parts 2. Prosthet Orthot Int. 2015; 39: 361-371. Ref.: https://goo.gl/HSBRpk

5. Conte MS. Bypass versus Angioplasty in Severe Ischaemia of the Leg (BASIL) and the (hoped for) dawn of evidence-based treatment for advanced limb ischemia. J Vasc Surg. 2010; 51(5 Suppl): 69S-75S. Ref.: https://goo.gl/R4UUR8

6. Klenow TD, Mengelkoch LJ, Stevens PM, Ràbago CA, Hill OT, et al. The role of exercise testing in predicting successful ambulation with a lower extremity prosthesis: a systematic literature review and clinical practice guideline. J Neuroeng Rehabil. 2018; 15(Suppl 1): 64. Ref.: https://goo.gl/Y3p5LC

7. Sanders JE, Fatone S. Residual limb volume change: Systematic review of measurement and management. J Rehabil Res Dev. 2011; 48: 949-986. Ref.: https://goo.gl/SGGe3G

8. Yahata T, Takeuchi A, Yoshida S, Tsuchiya H. Distinctive features of stump volume change in a fresh lower limb amputee with Parkes-Weber syndrome. BMJ Case Rep. 2014; 2014. pii: bcr2014206315. Ref.: https://goo.gl/fZ33fC

9. Highsmith MJ, Kahle JT, Klenow TD, Andrews $\mathrm{CR}$, Lewis $\mathrm{KL}$, et al. interventions to Manage Residual Limb Ulceration due to Prosthetic use in Individuals with Lower Extremity Amputation: A Systematic Review of the Literature. Technol Innov. 2016; 18: 115-123. Ref.: https://goo.gl/dWXT4H

10. Mendoza-Cruz F, Rodríguez-Reyes G, Galván Duque-Gastélum C, Alvarez-Camacho M. Comparative study of the volume difference vs. healthy limb, morphological and population description in transfemoral amputees. Rev Invest Clin. 2014; 66 Suppl 1: S85-93. Ref.: https://goo.gl/YW2Fti

11. Liu J, Lu N, Lou VWQ. Care tasks in the stress process for family caregivers in urban China. Clinical Gerontology. 2017; 40: 428-434. Ref.: https://goo.gl/Wf5uZq

12. Madsen UR, Hommel A, Bååth $C$, Berthelsen CB. Pendulating-A grounded theory explaining patients' behavior shortly after having a leg amputated due to vascular disease. Int J Qual Stud Health Wellbeing. 2016; 11: 32739. Ref.:

13. Rotariu M, Filep R, Turnea M, llea M, Arotăriţei D, Popescu M. Analyse of socket-prosthesis-blunt complex for lower limb amputee using objective measure of patient's gait cycle. Rev Med Chir Soc Med Nat lasi. 2015; 119: 281-286. https://goo.gl/SxRqrA

14. Murray CD, Simpson J, Eccles F, Forshaw MJ. Involvement in rehabilitative care and wellbeing for partners of people with an amputation. Psychol Health Med. 2015; 20: 71-76. Ref.: https://goo.gl/xJ3KKW

15. Mckechnie PS, John A. Anxiety and depression following traumatic limb amputation: a systematic review. Injury. 2014; 45: 1859-1866. Ref.: https://goo.gl/BfCyJ2

16. Horgan O, MacLachlan M. Psychosocial adjustment to lower-limb amputation: a review. Disabil Rehabil. 2004; 26: 837-850. Ref.: https://goo.gl/kwvjTB

17. Augustin $M$, Baade $K$, Heyer K, Price $P E$, Herberger $K$, et al. Quality-of-life evaluation in chronic wounds: comparative analysis of three disease-specific questionnaires. Int Wound J. 2017; 14 1299-1304. Ref.: https://goo.gl/kK7HRN 